\author{
С. Н. Гашев ${ }^{1, *}$, С. Г. Бабина ${ }^{2}$, С. Н. Бондарчук ${ }^{3}$, В. К. Васильева ${ }^{4}$, \\ Е. П. Выгузова ${ }^{5}$, И. В. Зенько ${ }^{6}$, А. В. Крутиков ${ }^{7}$ Е. В. Кулебякина ${ }^{8}$ Ю. П. Курхинен, \\ Д. С. Низовцев ${ }^{1}$, И. М. Охлопков ${ }^{4}$, А. П. Савельев ${ }^{11}$, Н. В. Сорокина ${ }^{1}$ \\ ${ }^{1}$ Тюменский государственный университет, Россия \\ *e-mail:gsn-61@mail.ru \\ 23 Заповедное Прибайкалье, Россия \\ ${ }^{3}$ Сихотэ-Алинский государственный природный биосферный заповедник им. К.Г. Абрамова, Россия \\ ${ }^{4}$ Институт биологических проблем криолитозоны СО РАН, Россия \\ ${ }^{5}$ Пермский краеведческий музей, Россия \\ ${ }^{6}$ Государственный заповедник «Малая Сосьва», Россия \\ ${ }^{7}$ Верхне-Тазовский заповедник, Россия \\ ${ }^{8}$ Национальный парк «Водлозерский», Россия \\ ${ }^{9}$ Университет Хельсинки, Финляндия \\ ${ }^{10}$ Институт леса Карельского научного иентра РАН, Россия \\ ${ }^{11}$ Всероссийский НИИ охотничьего хозяйства и звероводства им. Б.М. Житкова, Россия
}

Поступила: 10.06.2019. Исправлена: 10.09.2019. Принята к опубликованию: 12.09.2019.

\begin{abstract}
Pteromys volans заселяет значительную долю лесов умеренной зоны Евразии. В пределах ареала вид представлен 10 подвидами из разных районов ареала. При этом для диагностики подвидов используется такой морфологический показатель как окраска шкурки зверьков. В настоящей работе рассмотрены особенности окраски меха $P$. volans в разных географических точках ареала вида с учетом его внутривидовой дифференциации, определенные объективными методами по оригинальной методике авторов. В качестве диагностических показателей для описания мехового покрова предлагается использовать объективные колориметрические параметры - «белизну» и «оттенок красного», которые можно определить количественно через значения RGB (значения красного, зеленого и синего фильтров) в графических редакторах. Белизна представляет собой среднее арифметическое из значений показателей $\mathrm{R}, \mathrm{G}$ и B, а оттенок красного - отношение показателя R к белизне. Наименьшей белизной характеризуется мех зверьков подвидов P. volans, обитающих в приморских районах с более теплым и влажным климатом, а зверьки подвидов из глубины материка, характеризующегося более континентальным климатом, имеют в целом больший показатель белизны, наибольший в более северных широтах. Оттенок красного в окраске наибольший у зверьков подвидов P. volans, обитающих вблизи побережья Тихого океана. Проведенный дисперсионный анализ влияния таких климатических факторов, как влажность и температура, показал, что степень влияния влажности максимальна на оба показателя окраски и составляет $29.1 \%$ для белизны и $20.5 \%$ для оттенка красного цвета. Влияние температуры меньше и составляет соответственно $18.7 \%$ и $1.3 \%$. Совместное действие климатических факторов на белизну и оттенок красного составило соответственно $14.5 \%$ и $12.0 \%$. Наряду с экологическими факторами внутривидовая дифференциация окраски меха P. volans может объясняться и особенностями филогеографии его подвидов. В целом, исследования показали, что использованные колориметрические показатели меха, определенные с помощью графических редакторов по предложенной методике и оцененные статистически, адекватны и репрезентативны для изучения структуры вида P. volans.
\end{abstract}

Ключевые слова: белизна, графический редактор, Красная книга, оттенок красного цвета, подвид

\section{Введение}

Pteromys volans Linnaeus, 1758 населяет значительную долю лесов умеренной зоны Евразии (Shar et al., 2016). Во многих частях ареала вид редок или сокращает численность. Поэтому он включен в Красные книги 24 субъектов Российской Федерации (Лисовский и др.,
2019), в Красную книгу Республики Беларусь и в списки редких видов Финляндии и Эстонии. Pteromys volans представлен 10 подвидами из разных географических районов ареала (Огнев, 1940; Oshida et al., 2005; Павлинов, Лисовский, 2012): P. volans volans Linnaeus, 1758; P. volans ognevi Stroganov, 1936; P. volans gubari 
Ognev, 1935; P. volans betulinus Serebrennikov, 1929; P. volans turovi Ognev, 1929; P. volans athene Thomas, 1907; P. volans incanus Miller, 1918; P. volans arsenjevi Ognev, 1935; P. volans anadyrensis Ognev, 1940; P. volans orii Kuroda, 1921 (рис.). Имеются и другие подходы к внутривидовой дифференциации $P$. volans, ocнованные на молекулярно-генетических показателях (Oshida et al., 2005; Lee et al., 2008; Thorington et al., 2012; Yalkovskaya et al., 2015; Грицышин и др., 2017), в соответствие с которыми выделяются лишь 3 филогенетические группы внутри вида: «Хоккайдо», «Дальний Восток» и «Северная Евразия» (последняя делится на «Восток» и «Запад»).

Для диагностики традиционных подвидов используется такой морфологический показатель как окраска шкурки зверьков (Огнев, 1940), который является практически единственным диагностическим признаком и до сих пор. Однако, понятно, что показатели окраски шкурки, определяемые визуально и описываемые вербально, носят существенный субъективный характер. В такой ситуации появляется настоятельная потребность использования объективных критериев окраски, выраженных количественно и пригодных для статистической обработки. В настоящей работе мы рассмотрели особенности окраски меха $P$. volans в разных географических точках ареала вида с учетом его внутривидовой дифференциации, определенные объективными методами по оригинальной методике авторов.

Целью нашего исследования являлась оценка колориметрических характеристик шкурок летяги разных подвидов, обитающих в разных географических точках ареала вида.

\section{Материал и методы}

В ходе сбора первичного материала нами получены шкурки, сканы и фото 154 зверьков $P$. volans, относящихся к восьми подвидам из разных точек ареала: Финляндия, Эстония, Беларусь, Европейская Россия (Карелия, Псковская, Вологодская, Ленинградская области, Удмуртия, Кировская область, Пермский край), Западная Сибирь, Алтай, Красноярский край, Якутия, Забайкалье, Приморье, о. Сахалин и о. Хоккайдо. В данных регионах материал был собран на территории Байкало-Ленского заповедника, Сихотэ-Алинского государственного природного биосферного заповедника, государственного заповедника «Малая Сосьва», Верхне-Тазовского заповедника, национального парка «Водлозерский», комплексного заказника регионального значения «Юргинский», ресурсного резервата республиканского значения «Тамма» и ресурсного резервата местного значения «Кырбыкан». В настоящем анализе был использован 101 зверек $P$. volans из более полутора сотен. Остальные были отбракованы по качеству изображений или для соблюдения принципа прочих равных условий, т.к. нами исследовались лишь перелинявшие зверьки в зимнем меху.

В качестве диагностических цветовых показателей для описания мехового покрова мы предлагаем использовать объективные колориметрические параметры - «белизну» и «оттенок» (в данном случае - «оттенок красного»), предложенные в 1960-1980 гг. (Шварц и др., 1960; Покровский и др., 1962; Шварц, Покровский, 1966; Большаков, 1972; Добринский, 1981). Для этого использовался универсальный фотометр ФМ-3. В связи с развитием компьютерной техники, эти показатели можно определить количественно через значения RGB (значения красного, зеленого и синего фильтров графического файла) практически в любом графическом редакторе (Гашев, 2003) для конкретной точки изображения, представленного сканом или фотографией шкурки зверька (Гашев, 1999) с помощью инструмента «пипетка». Значение каждого показателя изменяется от 0 до 255 условных единиц. В настоящее время для анализа используются количественные параметры окраски биологических объектов как в России, так и за рубежом (Villafuerte \& Negro, 1998; Попов, 2005; Stevens et al., 2007; Bergman \& Beehner, 2009; Шмыров и др., 2012).

Для колориметрирования выбирался участок шкурки в области передней части спины, который обрабатывался в программе Adobe Photoshop по Гашеву (2003) с поправками на обработку скана или фотографий. Так, сканирование шкурки проводили со стандартными параметрами сканера, а фотографии рекомендовалось делать при дневном освещении без вспышки. Как для фотографий, так и для сканов рядом прикладывался листок белой бумаги для последующего приведения баланса белого каждого изображения по этому листку к показателям $\mathrm{RGB}$, равным 255 (для R), 255 (для G) и 255 (для B), т.е. полное отражение света. Чтобы нивелировать разницу в окраске отдельных волосков исследуемого участка шкурки он размывался с помощью фильтра «Gaussian Blur» (10 px). 


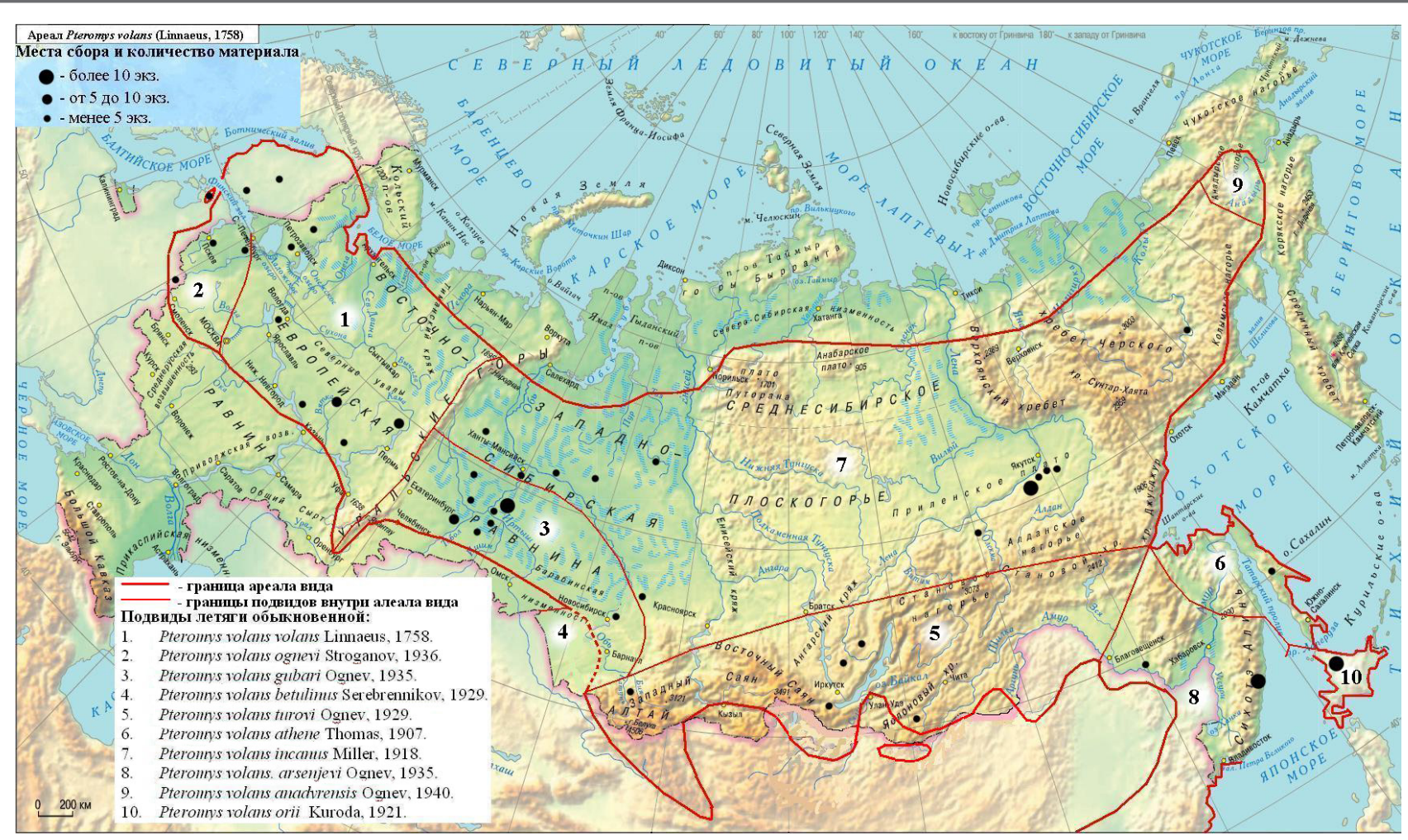

Рис. Ареал Pteromys volans с подвидами и объем исследованного материала. Обозначения: 1. P. volans volans; 2 . P. volans ognevi; 3. P. volans gubari; 4. P. volans betulinus; 5. P. volans turovi; 6. P. volans athene; 7. P. volans incanus; 8. P. volans arsenjevi; 9. P. volans anadyrensis; 10 . P. volans orii.

Fig. The Pteromys volans range with indication of subspecies' ranges and the amount of the studied data (dots). Designations: 1. P. volans volans; 2. P. volans ognevi; 3. P. volans gubari; 4. P. volans betulinus; 5. P. volans turovi; 6. P. volans athene; 7. P. volans incanus; 8. P. volans arsenjevi; 9. P. volans anadyrensis; 10 . P. volans orii.

Белизна представляет собой среднее арифметическое из значений показателей $\mathrm{R}, \mathrm{G}$ и B в каждой точке, а оттенок красного - отношение показателя R к белизне. Эти показатели по 10 точкам на изображении шкурки зверька усреднялись для использования в дальнейшей статистической обработке. Статистическая обработка материалов проведена с использованием программ MS Exel, Statistica 10 и STATAN-2003 по общепринятым методам.

\section{Результаты}

Для сравнения с $P$. volans мы определили и цветовые характеристики зимнего меха 8 экземпляров близкого вида Pteromys momonga Temminck, 1845, обитающего на Японских островах Кюсю и Хонсю. Результаты определения колориметрических показателей зимнего меха разных подвидов $P$. volans и P. momonga представлены в табл. 1.

Для определения степени влияния на показатели окраски зимнего меха летяг климатических условий местообитаний зверьков (среднегодовой влажности и температуры воздуха января (Национальный атлас России, 2019)) нами был проведен двухфакторный дисперсионный анализ, результаты которого обсуждаются ниже.
Таблица 1. Показатели белизны и оттенка красного цвета зимнего меха Pteromys volans и P. momonga

Table 1. Indicators of whiteness and shade of red colour of winter fur for Pteromys volans and P. momonga

\begin{tabular}{|l|c|c|c|}
\hline \multicolumn{1}{|c|}{$\begin{array}{c}\text { Подвид } \\
\text { летяги }\end{array}$} & $\mathrm{n}$ & $\begin{array}{c}\text { Белизна, } \\
\text { условные единицы }\end{array}$ & $\begin{array}{c}\text { Оттенок красного цвета, } \\
\text { условные единицы }\end{array}$ \\
\hline P. v. gubary & 54 & $108.17 \pm 5.975$ & $1.10 \pm 0.017$ \\
\hline P. v. volans & 22 & $145.47 \pm 5.376$ & $1.03 \pm 0.013$ \\
\hline P. v. athene & 2 & $88.77 \pm 15.167$ & $1.19 \pm 0.049$ \\
\hline P. v. incanus & 17 & $125.37 \pm 4.814$ & $1.07 \pm 0.019$ \\
\hline P. v. turovi & 5 & $108.78 \pm 10.438$ & $1.05 \pm 0.025$ \\
\hline P. v. arsenjevi & 12 & $91.958 \pm 3.810$ & $1.12 \pm 0.038$ \\
\hline P. v. ognevi & 5 & $99.880 \pm 14.889$ & $1.03 \pm 0.019$ \\
\hline P. v. orii & 23 & $151.54 \pm 5.884$ & $1.03 \pm 0.008$ \\
\hline P. momonga & 8 & $188.91 \pm 9.483$ & $1.08 \pm 0.019$ \\
\hline
\end{tabular}

\section{Обсуждение}

Анализируя данные табл. 1, видно, что наименьшей белизной характеризуется мех зверьков подвидов P. volans, обитающих в приморских районах с более теплым и влажным климатом (в порядке увеличения белизны $-P$. v. athene, $P$. v. arsenjevi и $P$. v. ogne$v i)$. Как на востоке, так и на западе ареала $P$. volans зверьки подвидов из глубины материка, характеризующегося более континентальным климатом, имеют в целом больший показа- 
тель белизны, наибольший в более северных широтах ( $P$. v. volans и $P$. v. incanus). Максимальные показатели белизны в пределах вида отмечены у зверьков $P$. v. orii, несмотря на географический район обитания зверьков (в приморском климате). Это же мы можем наблюдать и у представителей $P$. momonga. Оттенок красного в окраске наибольший у зверьков подвидов $P$. volans, обитающих вблизи побережья Тихого океана (P. v. athene, P. v. arsenjevi). Достоверность различий по t-критерию Стьюдента для этих двух показателей между подвидами приведена в табл. 2 и табл. 3. Видно, что по белизне достоверно от большинства других подвидов отличаются экземпляры $P$. v. volans и P. v. orii. Достоверны различия по белизне зверьков западной $P$. $v$ ognevi и восточной $P$. v. arsenjevi от особей северных подвидов из глубины материка (P. v. volans и P. v. incanus).

По оттенку красного цвета в зимнем мехе P. volans достоверных различий значительно меньше. В этом случае максимальное количество различий с другими подвидами отмечается у $P$. v. gubary, P. v. orii и P. v. athene (табл. 3). Причем P. v. ognevi, по белизне близкий к дальневосточным $P$. v. athene и $P$. v. arsenje- $v i$, по оттенку красного отличается от них в меньшую сторону.

Pteromys momonga по белизне отличается достоверно от всех подвидов $P$. volans, а по оттенку только от $P$. athene и от $P$. orii при $\mathrm{p}<0.05$.

Как мы можем заметить, территории, населенные зверьками таких подвидов, как $P$. v. volans и P. v. incanus достаточно велики как в широтном, так и долготном направлении (рис.). Возникает закономерный вопрос: насколько однородны эти группы зверьков по исследуемым нами показателям? Мы сравнили цветовые характеристики зимнего меха зверьков внутри этих двух подвидов. Для P. v. volans это были группы с северо-запада России и из Финляндии, из центральной России и из Пермского края. Ни по белизне, ни по оттенку красного цвета достоверных различий между ними не обнаружены. Для P. v. incanus сравнивали группы зверьков из Западной Сибири, Средней Сибири и из Якутии. Достоверных различий по исследуемым показателям также не обнаружено. Таким образом, в пределах рассматриваемых подвидов используемые для внутривидовой дифференциации цветовые параметры показали себя в целом как достаточно однородные, несмотря на имеющуюся изменчивость.

Таблица 2. Достоверность различий белизны зимнего меха разных подвидов Pteromys volans

Table 2. Reliability of difference for whiteness of winter fur of Pteromys volans subspecies

\begin{tabular}{|l|c|c|c|c|c|c|c|c|}
\hline Подвид летяги & P. v. gubary & P. v. volans & P. v. athene & P. v. incanus & P. v. turovi & P. v. arsenjevi & P. v. ognevi & P. v. orii \\
\hline P. v. gubary & & $\mathrm{p}<0.001$ & - & $\mathrm{p}<0.05$ & - & $\mathrm{p}<0.05$ & - & $\mathrm{p}<0.001$ \\
\hline P. v. volans & $\mathbf{4 . 5 6 1 7}$ & & $\mathrm{p}<0.01$ & $\mathrm{p}<0.05$ & $\mathrm{p}<0.01$ & $\mathrm{p}<0.001$ & $\mathrm{p}<0.01$ & - \\
\hline P. v. athene & 1.1200 & $\mathbf{3 . 0 6 4 0}$ & & $\mathrm{p}<0.05$ & - & - & - & $\mathrm{p}<0.01$ \\
\hline P. v. incanus & $\mathbf{2 . 2 6 2 0}$ & $\mathbf{2 . 7 0 0 0}$ & $\mathbf{2 . 4 5 5 2}$ & & - & $\mathrm{p}<0.001$ & $\mathrm{p}<0.05$ & $\mathrm{p}<0.01$ \\
\hline P. v. turovi & 0.0494 & $\mathbf{2 . 9 7 1 1}$ & 1.0411 & 1.5839 & & - & - & $\mathrm{p}<0.001$ \\
\hline P. v. arsenjevi & $\mathbf{2 . 1 5 9 3}$ & $\mathbf{6 . 8 2 6 0}$ & 0.2970 & $\mathbf{5 . 0 7 9 6}$ & 1.9125 & & - & $\mathrm{p}<0.001$ \\
\hline P. v. ognevi & 0.6248 & $\mathbf{3 . 4 4 9 8}$ & 0.4246 & $\mathbf{2 . 1 6 2 7}$ & 0.4894 & 0.7233 & $\mathbf{2}$ & $\mathrm{p}<0.01$ \\
\hline P. v. orii & $\mathbf{4 . 9 5 5 7}$ & 0.7602 & $\mathbf{3 . 0 4 5 7}$ & $\mathbf{2 . 2 6 7 9}$ & $\mathbf{5 . 4 8 8 2}$ & $\mathbf{6 . 8 9 4 7}$ & $\mathbf{3 . 6 0 3 2}$ & \\
\hline I. & & & & \\
\hline
\end{tabular}

Примечание: здесь и далее под штриховкой - абсолютные значения $\mathrm{T}_{\text {факт }}$ жирным шрифтом выделены достоверные различия; над штриховкой - уровень значимости различий.

Таблица 3. Достоверность различий оттенка красного цвета зимнего меха разных подвидов Pteromys volans Table 3. Reliability of differences for shade of red colour of winter fur of Pteromys volans subspecies

\begin{tabular}{|l|c|c|c|c|c|c|c|c|}
\hline Подвид летяги & P. v. gubary & P. v. volans & P. v. athene & P. v. incanus & P. v. turovi & P. v. arsenjevi & P. v. ognevi & P. v. orii \\
\hline P. v. gubary & & $\mathrm{p}<0.01$ & - & - & - & - & $\mathrm{p}<0.05$ & $\mathrm{p}<0.001$ \\
\hline P. v. volans & $\mathbf{3 . 2 9 0 0}$ & & $\mathrm{p}<0.001$ & - & - & $\mathrm{p}<0.05$ & - & - \\
\hline P. v. athene & 1.7623 & $\mathbf{3 . 3 6 4 0}$ & & - & $\mathrm{p}<0.05$ & - & $\mathrm{p}<0.05$ & $\mathrm{p}<0.001$ \\
\hline P. v. incanus & 1.1779 & 1.7392 & 1.9818 & & - & - & - & - \\
\hline P. v. turovi & 1.6311 & 0.5655 & $\mathbf{2 . 8 9 5 3}$ & 0.5845 & & - & - & - \\
\hline P. v. arsenjevi & 0.3397 & $\mathbf{2 . 5 4 7 6}$ & 0.7742 & 1.1257 & 1.0896 & & - & $\mathrm{p}<0.01$ \\
\hline P. v. ognevi & $\mathbf{2 . 3 9 1 3}$ & 0.1615 & $\mathbf{3 . 9 6 3 9}$ & 1.1851 & 0.7135 & 1.4726 & & - \\
\hline P. v. orii & $\mathbf{3 . 9 4 4 4}$ & 0.2158 & $\mathbf{5 . 0 3 3 7}$ & 1.8953 & 0.6629 & $\mathbf{2 . 7 6 7 2}$ & 0.4127 & \\
\hline
\end{tabular}


В тоже время, нами обнаружены статистически достоверные различия по изучаемым цветовым показателям между соседними группами зверьков граничащих подвидов, например, между зверьками $P$. v. gubary в Западной Сибири и зверьками из Пермского края $P$. v. volans. Эта особенность дает основание считать, что границы между подвидами, выделенными по цветовым показателям меха зверьков Огневым (1940) реальны, а Уральские горы все же могут играть определенную барьерную роль, хотя это иногда и ставится под сомнение (Yalkovskaya et al., 2015; Грицышин и др., 2017).

Проведенный выше анализ позволяет предположить, что географические различия в окраске зимнего меха летяги соответствуют экологическому правилу Глогера. Для подтверждения этого нами был проведен двухфакторный дисперсионный анализ. В качестве действующих факторов рассматривались температура (средняя многолетняя температура января) и влажность (средняя многолетняя влажность января). Дисперсионный анализ показал, что доля влияния влажности максимальна на оба показателя окраски и составляет $29.1 \%$ для белизны и $20.5 \%$ для оттенка красного цвета. Влияние температуры меньше и составляет соответственно $18.7 \%$ и $1.3 \%$. Совместное действие климатических факторов на белизну и оттенок красного составило соответственно $14.5 \%$ и $12.0 \%$. Таким образом, на долю прочих неконтролируемых факторов, влияющих на общую белизну, которая и определяет ее такие свойства как «светлое - темное» (независимо от оттенка), приходится лишь $37.7 \%$.

Тем не менее, как мы отмечали выше, эти экологические закономерности не действуют в отношении такого подвида как $P$. v. orii, обитающем на о. Хоккайдо. Не действует правило Глогера и в отношении P. momonga, которая значительно светлее всех $P$. volans и характеризуется невысоким показателем оттенка красного в мехе. Этот факт, видимо, можно объяснить только филогенетическими причинами, связанными с тем, что время отделения подвида $P$. v. orii от $P$. v. arsenjevi (предположительно исходный тип) значительно больше, чем у других материковых подвидов, включая и $P$. v. athene. Но еще раньше произошло обособление P. momonga. Согласно Yalkovskaya et al. (2015), «время расхождения P. volans P. momonga около 450 тыс. лет назад. Первая дивергенция $P$. volans на группы «Дальний Восток» и группу, включающую позже разделившиеся «Северная Евразия» и «Хоккайдо», произошла около 240 тыс. лет назад. Время изоляции островной группы «Хоккайдо» около 200 тыс. лет назад. Начало внутренней дифференциации групп «Дальний Восток» и «Северная Евразия» - период 200-120 тыс. лет назад. Только позднее $P$. volans стали расселяться на северо-восток (в том числе на о. Сахалин $-P$. v. athene) и на запад, сначала по южным районам лесной зоны (современные более темные подвиды $P$. v. turovi, $P$. v. gubary и P. v. ognevi), постепенно проникая также все дальше и дальше на север, формируя современные более светлые подвиды $P$. v. incanus и P. v. volans.

Сравнивая полученные нами объективные показатели окраски меха P. volans разных подвидов с используемыми другими авторами ранее субъективными параметрами для диагностики этих подвидов, можно констатировать, что они иногда не вполне совпадают. Так, например, Огнев (1940) писал, что P. v. gubari отличается от европейских форм более светлым, серебристо-серым тоном спины в зимнем меху, в то время как наши исследования показали, что этот подвид темнее и это сближает его с $P$. v. turovi. Так же и зверьки $P$. v. athene по нашим данным темнее $P$. v. turovi, хотя Огнев (1940) указывал обратное.

\section{Заключение}

В целом исследования показали, что такие колориметрические показатели меха зверьков как «белизна» и «оттенок красного», определенные с помощью графических редакторов по предложенной нами методике и оцененные статистически вполне адекватны и репрезентативны для изучения структуры вида $P$. volans. Проведенные нами исследования показывают необходимость дальнейших работ в этой области с привлечением большего материала и из большего числа географических пунктов ареала, причем зверьков, как в зимнем, так и в летнем меху (в т.ч. с измерениями окраски хвоста, который тоже предлагался для использования при внутривидовой диагностике) (Огнев, 1940). При этом для анализа внутривидовой дифференциации $P$. volans интересны будут сопоставления полученных нами результатов с данными молекулярно-генетических исследований. 


\section{Благодарности}

Авторы выражают благодарность М. Антипину, Д. Дерунову, Б. Жумабековой, Ю. Мишлановой, Т. Орловой, П. Ситникову и И. Халитову за предоставленные материалы и информацию для настоящего исследования.

\section{Литература}

Большаков В.Н. 1972. Пути приспособления мелких млекопитающих к горным условиям. М.: Наука. 199 с.

Гашев С.Н. 1999. Фотоколориметрирование шкурок млекопитающих с помощью цветного сканера к IBM PC // Материалы VI Съезда ВТО РАН. М.: Изд-во Россельхозакадемии. С. 57.

Гашев С.Н. 2003. Новые методические подходы к определению цветовых характеристик биологических объектов // Успехи современного естествознания. №1. C. 23-27.

Грицышин В.А., Артюшин И.В., Белоконь М.М., Захаров Е.С., Авилова К.В., Абрамов А.В., Низовцев Д.С., Гашев С.Н., Политов Д.В., Банникова А.А. 2017. Новые данные о филогеографии обыкновенной летяги Pteromys volans (Linnaeus, 1758) и происхождении популяции на юго-западе Московского региона // Генетика популяций: прогресс и перспективы. М.: МГУ. С. $84-85$.

Добринский Л.Н. 1981. Динамика морфофизиологических особенностей птиц. М.: Наука. 124 с.

Национальный атлас России. 2019. Available from https:// национальныйатлас.pф/cd2/158-159/158-159.htm

Лисовский А.А., Шефтель Б.И., Савельев А.П., Ермаков О.А., Козлов Ю.А., Смирнов Д.Г., Стахеев В.В., Глазов Д.М. 2019. Млекопитающие России: список видов и прикладные аспекты // Сборник трудов Зоологического музея МГУ. Том 56. С. 1-191.

Огнев С.И. 1940. Звери СССР и прилежащих стран. Грызуны. Том 4. М.-Л.: Издательство Академии наук СССР. $616 \mathrm{c}$.

Павлинов И.Я., Лисовский А.А. 2012. Млекопитающие России: систематико-географический справочник. М.: Тов-во научных изданий КМК. 604 с.

Покровский А.В., Смирнов В.С., Шварц С.С. 1962. Колориметрическое изучение изменчивости окраски грызунов в экспериментальных условиях в связи с проблемой гибридных популяций // Вопросы внутривидовой изменчивости млекопитающих. Труды Института биологии УФАН СССР. Вып. 29. С. 15-28.

Попов П.П. 2005. Фотоколориметрическая оценка семян ели // Лесоведение. №4. С. 78-80.

Шварц С.С., Копеин К.И., Покровский А.В. 1960. Сравнительное изучение некоторых биологических особенностей полевок Microtus gregalis Pall., M. g. major Ogn. и их помесей // Зоологический журнал. T. 39(6). С. 912-926.

Шварц С.С., Покровский А.В. 1966. Опыт сближения специфической подвидовой окраски двух резко дифференцированных подвидов путем отбора и лабораторных популяций // Зоологический журнал. Т. 45(1). C. 119-124.
Шмыров А.А., Кузьмин Ан.А., Кузьмин Ал.А., Титов C.В. 2012. Характеристика гибридов большого (Spermophilus major) и желтого (Spermophilus fulvus) сусликов по морфологическим и акустическим признакам // Зоологический журнал. Т. 91(1). С. 119-126.

Bergman T.J., Ho L., Beehner J.C. 2009. Chest Color and Social Status in Male Geladas (Theropithecus gelada) // International Journal of Primatology. Vol. 30(6). P. 791-806. DOI: 10.1007/s10764-009-9374-X

Lee M.Y., Park S.K., Hong Y.J., Kim Y.J., Voloshina I., Myslenkov A., Saveljev A.P., Choi T.Y., Piao R.-Z., An J.H., Lee M.H., Lee H., Min M.S. 2008. Mitochondrial genetic diversity and phylogenetic relationships of Siberian flying squirrel (Pteromys volans) populations // Animal Cells and Systems. Vol. 12(4). P. 269-277. DOI: $10.1080 / 19768354.2008 .9647182$

Oshida T., Abramov A., Yanagawa H., Masuda R. 2005. Phylogeography of the Russian flying squirrel (Pteromys volans): implication of refugia theory in arboreal small mammal of Eurasia // Molecular Ecology. Vol. 14(4). P. 1191-1196. DOI: 10.1111/j.1365-294X.2005.02475.x

Shar S., Lkhagvasuren D., Henttonen H., Maran T., Hanski I. 2016. Pteromys volans // The IUCN Red List of Threatened Species. Available from http:// dx.doi.org/10.2305/IUCN.UK.2016-3.RLTS. T18702A22270935.en

Stevens M, Párraga C.A., Cuthill I.C., Partridge J.C., Troscianko T.S. 2007. Using digital photography to study animal coloration // Biological Journal of the Linnean Society. Vol. 90(2). P. 211-237. DOI: 10.1111/j.1095-8312.2007.00725.x

Thorington R.W., Koprowski J.L., Steele M.A., Whatton J.F. 2012. Squirrels of the World. Baltimore, Maryland: Johns Hopkins University Press. 459 p.

Villafuerte R., Negro J.J. 1998. Digital imaging for colour measurement in ecological research // Ecology Letters. Vol. 1(3). P. 151-154. DOI: 10.1046/j.14610248.1998.00034.x

Yalkovskaya L.E., Bolshakov V.N., Sibiryakov P.A., Borodin A.V. 2015. Phylogeography of the Siberian flying squirrel (Pteromys volans L., 1785) and the history of the formation of the modern species range: New data // Doklady Biochemistry and Biophysics. Vol. 462(1). P. 181-184. DOI: 10.1134/S1607672915030114

\section{References}

Bergman T.J., Ho L., Beehner J.C. 2009. Chest Color and Social Status in Male Geladas (Theropithecus gelada). International Journal of Primatology 30(6): 791-806. DOI: 10.1007/s10764-009-9374-x

Bolshakov V.N. 1972. Ways of adaptation of small mammals to mountain conditions. Moscow: Nauka. 199 p. [In Russian]

Dobrinskiy L.N. 1981. Dynamics of morphophysiological features of birds. Moscow: Nauka. 124 p. [In Russian]

Gashev S.N. 1999. Photocolourimetry of mammalian skins using a colour scanner for IBM PC. In: Materials of the VI Congress of the RTS RAS. 
Moscow: Publishing house of the Russian Agricultural Academy. 57 p. [In Russian]

Gashev S.N. 2003. New methodological approaches to determining the colour characteristics of biological objects. Successes of Modern Natural Science 1: 23-27. [In Russian]

Gritsyshin V.A., Artyushin I.V., Belokon M.M., Zakharov E.S., Avilov K.V., Abramov A.V., Nizovtsev D.C., Gashev S.N., Politov D.V., Bannikova A.A. 2017. New data on the phylogeography of common flying squirrel Pteromys volans (Linnaeus, 1758) and the origin of the population in the South-West of the Moscow region. In: Population Genetics: Progress and Prospects. Moscow: MSU Press. P. 84-85. [In Russian]

Lee M.Y., Park S.K., Hong Y.J., Kim Y.J., Voloshina I., Myslenkov A., Saveljev A.P., Choi T.Y., Piao R.-Z., An J.H., Lee M.H., Lee H., Min M.S. 2008. Mitochondrial genetic diversity and phylogenetic relationships of Siberian flying squirrel (Pteromys volans) populations. Animal Cells and Systems 12(4): 269-277. DOI: 10.1080/19768354.2008.9647182

Lissovsky A.A., Sheftel B.I., Saveljev A.P., Ermakov O.A., Kozlov Yu.A., Smirnov D.G., Stakheev V.V., Glazov D.M. 2019. Mammals of Russia: species list and applied aspects. Archives of Zoological Museum of Moscow State University. Vol. 56: 1-191. [In Russian]

National Atlas of Russia. 2019. Available from https:// национальныйатлас.pф/cd2/158-159/158-159.htm. [In Russian]

Ognev S.I. 1940. Animals of the USSR and the surrounding countries. Rodents. Vol. 4. Moscow; Leningrad: Publisher of AS USSR. 616 p. [In Russian]

Pavlinov I.Ya., Lissovsky A.A. 2012. Mammals of Russia: a systematic-geographical guide. Moscow: Moscow: KMK Scientific Press Ltd. 604 p. [In Russian]

Oshida T, Abramov A, Yanagawa H, Masuda R. 2005. Phylogeography of the Russian flying squirrel (Pteromys volans): implication of refugia theory in arboreal small mammal of Eurasia. Molecular Ecology 14(4): 11911196. DOI: 10.1111/j.1365-294X.2005.02475.x

Pokrovsky A.V., Smirnov V.S., Schwartz S.S. 1962. Colourimetric study of rodent colour variability in experimental conditions in connection with the problem of hybrid populations. In: Questions of intraspecific variability of mammals. Proceedings of the Institute of biology Ural Branch of AS USSR 29: 15-28. [In Russian]

Popov P.P. 2005. Photocolourimetric evaluation of spruce seeds. Lesovedenie 4: 78-80. [In Russian]

Shar S., Lkhagvasuren D., Henttonen H., Maran T., Hanski I. 2016. Pteromys volans. In: The IUCN Red List of Threatened Species. Available from: http://dx.doi.org/10.2305/IUCN.UK.2016-3.RLTS. T18702A22270935.en

Shmyrov A.A., Kuzmin An.A., Kuzmin Al.A., Titov S.V. 2012. Characterization of hybrids between the russet (Spermophilus major) and the yellow (Spermophilus fulvus) ground squirrels according to morphological and acoustic attributes. Zoologicheskii Zhurnal 91(1): 119-126. [In Russian]

Shvarts S.S., Kopein K.I., Pokrovskiy A.V. 1960. Comparative study of some biological features of voles Microtus gregalis Pall., M. g. major Ogn. and their hybrids. Zoologicheskii Zhurnal 39(6): 912-926. [In Russian]

Shvarts S.S., Pokrovskiy A.V. 1966. Experience the colouring convergence of specific subspecies of two extremely differentiated subspecies by sampling and laboratory populations. Zoologicheskii Zhurnal 45(1): 119-124. [In Russian]

Stevens M, Párraga C.A., Cuthill I.C., Partridge J.C., Troscianko T.S. 2007. Using digital photography to study animal coloration. Biological Journal of the Linnean Society 90(2): 211-237. DOI: 10.1111/j.10958312.2007.00725.x

Thorington R.W., Koprowski J.L., Steele M.A., Whatton J.F. 2012. Squirrels of the World. Johns Baltimore, Maryland: Hopkins University Press. 459 p.

Villafuerte R., Negro J.J. 1998. Digital imaging for colour measurement in ecological research. Ecology Letters 1(3): 151-154. DOI: 10.1046/j.14610248.1998.00034.x

Yalkovskaya L.E., Bolshakov V.N., Sibiryakov P.A., Borodin A.V. 2015. Phylogeography of the Siberian flying squirrel (Pteromys volans L., 1785) and the history of the formation of the modern species range: New data // Doklady Biochemistry and Biophysics. Vol. 462(1). P. 181-184. DOI: 10.1134/S1607672915030114 


\title{
INTRASPECIES DIFFERENTIATION OF WINTER FUR COLOURING OF PTEROMYS VOLANS (SCIURIDAE, MAMMALIA) WITHIN ITS RANGE
}

\author{
Sergey N. Gashev 1,*, Svetlana G. Babina ${ }^{2}$, Svetlana N. Bondarchuk ${ }^{3}$, Vera K. Vasilyeva ${ }^{4}$, \\ Evgenia P. Vyguzova ${ }^{5}$, Igor V. Zenjko ${ }^{6}$, Aleksey V. Krutikov ${ }^{7}$, Elena V. Kulebyakina ${ }^{8}$, Juri P. Kurhinen ${ }^{9,10}$, \\ Dmitry S. Nizovtsev ${ }^{1}$, Innokentiy M. Okhlopkov ${ }^{4}$, Alexander P. Savelyev ${ }^{11}$, Natalya V. Sorokina ${ }^{1}$
}

\author{
${ }^{1}$ Tyumen State University, Russia \\ e-mail:gsn-61@mail.ru \\ ${ }^{2}$ Zapovednoe Pribaikalye, Russia \\ ${ }^{3}$ K. G. Abramov Sikhote-Alin State Nature Biosphere Reserve, Russia \\ ${ }^{4}$ Institute for Biological Problems of Cryolithozone of SB RAS, Russia \\ ${ }^{5}$ Perm Museum of Local Lore, Russia \\ ${ }^{6}$ State Nature Reserve «Malaya Sosva», Russia \\ ${ }^{7}$ Verkhne-Tazovsky State Nature Reserve, Russia \\ ${ }^{8}$ Vodlozersky National Park, Russia \\ ${ }^{9}$ Helsinki University, Finland \\ ${ }^{10}$ Forestry Research Institute of Karelian Research Centre RAS, Russia \\ ${ }^{11}$ B.M. Zhitkov Russian Research Institute of Game Management and Fur Farming, Russia
}

\begin{abstract}
Pteromys volans (Siberian flying squirrel) inhabits major part of temperate forests in Eurasia. The species is represented by 10 subspecies within its range. To distinguish the subspecies, such a morphological indicator as the skin colouring is used. This article represents the peculiarities of the Siberian flying squirrel's fur colouring in different areas of the species range taking into account the intraspecific fur differentiation. The latter is determined using the original author's methodics. We propose to use objective colourimetric parameters («whiteness» and «shade of red colour») as diagnostic indicators for describing the fur cover. It can be quantified using RGB values (values of red, green and blue filtres) in almost any graphic editor. Whiteness is the arithmetic mean of the $R, G$ and $B$ values, while the shade of red colour is the ratio of $\mathrm{R}$ to whiteness. The fur of subspecies individuals inhabiting coastal regions with a warmer and more humid climate is characterised by the lowest whiteness. Subspecies individuals from the continental regions characterising by a more continental climate have generally greater whiteness and the highest values of whiteness are recorded in areas located at more northern latitudes. The value of the shade of red colour was higher in the colouration among the P. volans subspecies living near the Pacific Ocean coast. The dispersion analysis of the climatic factor effects (humidity and temperature) showed that the degree of humidity influence was maximal in both colour indicators, and it amounts $29.1 \%$ for whiteness and $20.5 \%$ for a shade of red colour. The temperature effect was less than humidity effect; it accounted for $18.7 \%$ for whiteness and $1.3 \%$ for a shade of red colour. The combined effect of these climatic factors on the whiteness and shade of red colour was $14.5 \%$ and $12.0 \%$, respectively. Besides of environmental factors, the intraspecific differentiation of the $P$. volans fur colour could also be explained by the peculiarities of its subspecies phylogeography. In general, we have demonstrated that the used colourimetric fur indicators, being determined by the proposed method, were estimated to be statistically adequate and representative to distinguish the subspecies of $P$. volans.
\end{abstract}

Key words: graphic editor, Red Data Book, shade of red colour, subspecies, whiteness 